\title{
Nervous System and Gastrointestinal Effects of the Insecticide Esfenvalerate on the Rat: An Ex Vivo Study
}

\author{
Petra Varró ${ }^{1,2 *}$, Eszter Szabóo', Melinda Kovács², Ildikó Világi ${ }^{1}$ \\ ${ }^{1}$ Department of Physiology and Neurobiology, Eötvös Loránd University, Budapest, Hungary \\ ${ }^{2}$ MTA-KE Mycotoxins in the Food Chain Research Group, Kaposvár, Hungary \\ Email: ${ }^{*}$ varro.petra@ttk.elte.hu
}

Received 16 January 2014; revised 26 February 2014; accepted 14 March 2014

Copyright (C) 2014 by authors and Scientific Research Publishing Inc.

This work is licensed under the Creative Commons Attribution International License (CC BY).

http://creativecommons.org/licenses/by/4.0/

(c) (i) Open Access

\begin{abstract}
Esfenvalerate belongs to the pyrethroid group of insecticides which display significant selective toxicity against insects compared to mammalian species, nevertheless, they may pose health risks, especially in case of accidental exposure. The aim of the present study was to model the effect of acute, relatively high-dose exposure of the esfenvalerate-containing formulation Sumi-Alpha ${ }^{\circledR}$. Eventual functional alterations in the central nervous system and in the gastrointestinal tract were studied on in vitro tissue preparations at different delays after intragastric administration to rats. Neuronal effects were characterized by field potential recording in cortical and hippocampal brain slices, while gastrointestinal effects were examined by analyzing the motility and excitability of isolated ileum segments. On the brain slices originating from esfenvalerate-treated animals, changes in excitability of both inhibitory and excitatory type could be observed. Voltage thresholds necessary to evoke responses in neocortex slices were elevated, and population spike amplitudes were lower in hippocampal slices. However, epileptiform potentials with pronounced late components were also observed. A decreased long-term potentiation (LTP) could be seen in both brain areas after esfenvalerate treatment. Seizure susceptibility of the slices was not significantly altered, but tended to be somewhat higher in slices originating from treated rats. In ileum segments, both spontaneous and acetyl-choline (ACh)-elicited contractions were modified by treatment. Esfenvalerate raised the amplitude of contractions in the low ACh concentration range. However, the solvent xylene also considerably contributed to the detected changes. We can conclude that a relatively high, single oral dose of Sumi-Alpha ${ }^{\circledR}$ exerted mild and temporary effects on the elementary brain functions and intestine functions of the rat.
\end{abstract}

\footnotetext{
"Corresponding author.
} 


\section{Keywords}

\section{Pyrethroid; Ileum Motility; Brain Slice; Field Potentials}

\section{Introduction}

Pyrethroids are widely used insecticides in agriculture, veterinary medicine and public health. They are the synthetic analogues of pyrethrins, compounds extracted from Chrysanthemum flowers [1]. The pyrethroid group contains ester type molecules with a wide diversity concerning their exact chemical structure. Pyrethroids present higher insecticidal efficacy and environmental stability than their natural precursors. Esfenvalerate was registered in 1986; it contains the most insecticidally active (S,S-) stereoisomer of fenvalerate in high percentage.

Pyrethroid insecticides exert their effects mainly on the central nervous system, causing hyperactive poisoning symptoms. Their mechanism of action is the modification of the gating kinetics of voltage-gated sodium channels [2]. Voltage-gated sodium channels are responsible for action potential generation in most neurons and other electrically excitable cells, contributing to signal transmission [3] [4]. Normally, these channels remain open only for about $1 \mathrm{~ms}$, before being inactivated, then closed. Voltage-clamp studies have shown that pyrethroids slow down both activation and inactivation kinetics of the channels, leading to depolarizing after potentials [5]. If a sufficient fraction of channels is modified, the after potential reaches the cell's threshold for excitation and repetitive after discharges are produced which are in the background of the poisoning symptoms [6].

Orally administered esfenvalerate is rapidly eliminated from the body [7]. Fenvalerate exposure, at a dose level which produces acute poisoning, does not lead to brain lesions [8]. Notwithstanding, more or less long-lasting functional changes may be induced by esfenvalerate intoxication.

In case of an accidental ingestion of pyrethroids, aside from the central nervous system, the gastrointestinal tract is another primary target, being the site of absorption. Esfenvalerate may modify the regulation of intestine movements and secretory functions. The gut smooth muscle has a spontaneous myogenic activity; it is able to contract independently from the central nervous system. The regulation in the gut is assured by the enteric nervous system, containing whole reflex circuits [9]. Enteric neurons form two major plexuses, which lay between the gut muscle layers and the mesenteria. The myenteric plexus extends the entire length of the gut, and its role is rather motility coordination, while the submucous plexus, present only in the small intestine, plays an important role in secretory control [10]. In enteric neurons, more than 20 neurotransmitter types have been identified. Acetyl-choline (ACh) acting on nicotinic and muscarinic receptors exerts an excitatory effect on smooth muscle contraction both on the level of interneurons, motoneurons and smooth muscle cells [9].

The aim of the present study was to test the effects of the pyrethroid insecticide esfenvalerate on a mammalian model, the rat. To model a relatively high-dose, accidental exposure, a single dose corresponding to the quarter of the oral $\mathrm{LD}_{50}$ was administered intragastrically to the animals. Data were acquired at different delays after treatment (1 - 7 days) to provide some indications about the dynamics of the poisoning. The study focused on eventual functional alterations in the gastrointestinal tract and in the central nervous system. Gastrointestinal effects were studied by analyzing the motility and excitability of isolated ileum segments. Effects on the nervous system were studied using surviving brain slices. Extracellular electrophysiological recordings were performed in two brain regions, the somatosensory cortex and the hippocampus. Basic synaptic activity, synaptic plasticity and seizure susceptibility were analyzed.

\section{Materials and Methods}

\subsection{Animal Maintenance and Treatment}

The experiments were performed on young adult, male Wistar rats (100 - 250 g, Toxi-coop Ltd., Budapest, Hungary). The experimental design had been approved by Eötvös Loránd University Animal Care Committee and by the Hungarian National Animal Health Care Authority. The rats were kept under a constant 12-h light/dark cycle at controlled temperature $\left(22^{\circ} \mathrm{C} \pm 2^{\circ} \mathrm{C}\right)$. Standard pellet food (Toxi-coop Ltd.) and tap water were available ad libitum.

Rats were treated with Sumi-Alfa ${ }^{\circledR}$ by gavage. The commercial product (containing xylene as a solvent) was 
diluted $5 \times$ in physiological salt solution $(0.9 \mathrm{~g} \mathrm{NaCl}$ in $100 \mathrm{ml}$ distilled water), the applied active ingredient dose was $20 \mathrm{mg} / \mathrm{bwkg}$ (injected volume: $0.2-0.5 \mathrm{ml}$ ). There were two control groups which received physiological salt solution or the appropriate dose of solvent (xylene) dissolved in physiological salt solution. The treated animals were sacrificed 1, 2 or 7 days after gavage (these will be referred to as "one-day, two-day and seven-day" groups for simplicity) and the "xylene" and "phys. salt" control animals 1 day after gavage. Animal numbers in different groups were: phys. salt control—8; xylene control—8; one-day—7; two-day—7; seven-day—8.

\subsection{Chemicals}

Sumi-Alpha 5-EC ${ }^{\circledR}$ was purchased from Sumitomo Chemical Co. Ltd., Japan. All other compounds were purchased from Sigma-Aldrich Co., Budapest, Hungary.

\subsection{Electrophysiological Recording on Brain Slices}

Experiments were performed as it was detailed in earlier papers [11]. Shortly, after decapitation, the brain was quickly removed and coronal slices ( $400 \mu \mathrm{m}$ thick) containing the somatosensory cortex and the hippocampus were cut with a vibratome (Electron Microscopy Sciences, Hatfield, USA). Slices were incubated at room temperature for an hour in artificial cerebrospinal fluid (ACSF) oxygenated with carbogen and buffered with HEPES (N-2-hydroxyethylpiperazine-N-2-ethanesulfonic acid and its sodium salt, $\mathrm{pH} 7.1$ - 7.2), the composition of which was (in mM): $120 \mathrm{NaCl} ; 2 \mathrm{KCl} ; 1.25 \mathrm{KH}_{2} \mathrm{PO}_{4} ; 2 \mathrm{MgSO}_{4} ; 20 \mathrm{NaHCO}_{3} ; 2 \mathrm{CaCl}_{2} ; 10$ glucose; 6.7 HEPES—acid; 3.3 HEPES-Na.

Slices were then placed into an interface type recording chamber (FST Ltd., North Vancouver, Canada), through which standard ACSF was perfused ( $2.5 \mathrm{ml} / \mathrm{min})$. The composition of the ACSF solution was (in $\mathrm{mM}$ ): $126 \mathrm{NaCl} ; 26 \mathrm{NaHCO}_{3} ; 1.8 \mathrm{KCl} ; 1.25 \mathrm{KH}_{2} \mathrm{PO}_{4} ; 1.3 \mathrm{MgSO}_{4} ; 2.4 \mathrm{CaCl}_{2} ; 10$ glucose (pH: 7.4). The solution was saturated with carbogen at $33^{\circ} \mathrm{C} \pm 1^{\circ} \mathrm{C}$.

Electrical single-shock stimulation was used to elicit field excitatory postsynaptic potentials (fEPSPs) in the neocortex. Similarly, electrically evoked responses were recorded in the hippocampus, population spikes (POPspikes) sitting on the EPSP curve were detected with extracellular glass microelectrodes (5 - $10 \mathrm{M} \Omega$ ) filled with $1 \mathrm{M} \mathrm{NaCl}$. In case of the neocortical slices, the recording electrodes were positioned in the lower part of layer III of the neocortex and bipolar tungsten stimulation electrodes were positioned immediately below the recording electrodes at the border of the white and grey matter. In the hippocampal slices, stimulation electrodes were placed at the Schaffer collaterals and the recording electrodes into the stratum pyramidale of the CA1 region. The duration of the square voltage pulses was $100 \mu$ s (BioStim, Supertech Ltd., Pécs, Hungary). Signals were band-pass filtered $(0.16 \mathrm{~Hz}-1 \mathrm{kHz})$ and amplified 1000× (BioAmp, Supertech Ltd., Pécs, Hungary), A/D converted and recorded with the SPEL Advanced Intrasys computer program (Experimetria Ltd., Budapest, Hungary).

Before recording, the viability of each slice was tested. If the peak-to-peak amplitude of the maximum evoked response was smaller than $1 \mathrm{mV}$, the slice was excluded from the experiments. Basic synaptic functions were tested by determining the voltage threshold of the evoked field potential (T), and then a stimulation intensity of $2 \mathrm{~T}$ was applied to record "test stimulation". Test stimulation recording was followed by the induction of longterm potentiation (LTP) by repetitive stimulation in order to investigate long-term synaptic plasticity. The stimulation parameters were as follows: intensity $-2 \mathrm{~T}$, frequency $-100 \mathrm{~Hz}$, duration $-5 \mathrm{~s}$, 4 times with $10 \mathrm{~s}$ breaks. Subsequently, test stimulation was carried out with $0.1 \mathrm{~Hz}$ during $30 \mathrm{~min}$ at $2 \mathrm{~T}$. Finally, responses evoked by test stimulation were recorded (“after LTP”). On some neocortex slices, seizure susceptibility was tested by applying ACSF containing $20 \mu \mathrm{M}$ 4-aminopyridine (4-AP) for $60 \mathrm{~min}$. Spontaneous activity was recorded with a paper chart recorder (Gould, Eichstetten, Germany), the latency time and frequency of seizure-like events was measured. Before and after perfusion with 4-AP, evoked test responses were also recorded (stimulation intensity: $2 \mathrm{~T}$ ).

Stored signals were analyzed with the SPEL Advanced Intrasys computer program. In neocortical slices, at test stimulation intensity, characteristically an early (N1) and a late (N2) negative peak appeared following the stimulation, with a latency of 4 - $5 \mathrm{~ms}$ and 15 - $20 \mathrm{~ms}$, respectively. The two negative peaks were usually separated by a positive peak (P1). The amplitude of the early component of fEPSPs was measured as the peak-topeak amplitude N1-P1 and the late component as the maximal peak of N2 (Figure 1(A)). In the hippocampal 
A

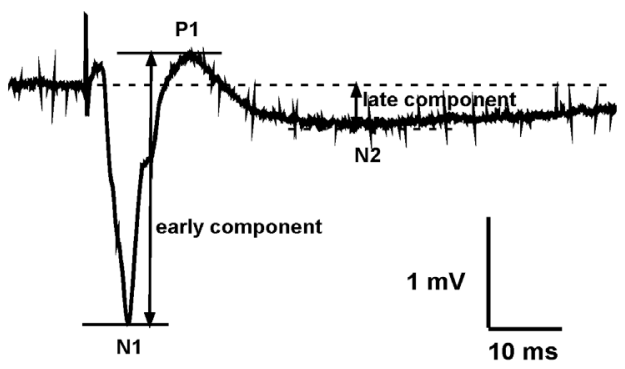

B

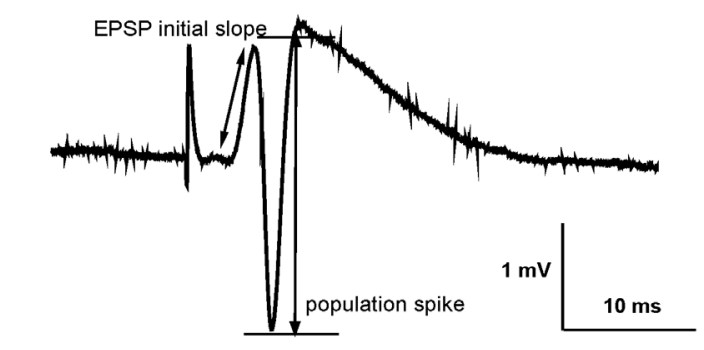

C

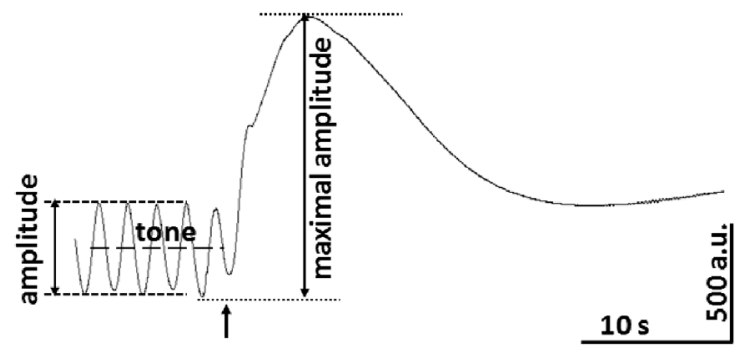

D

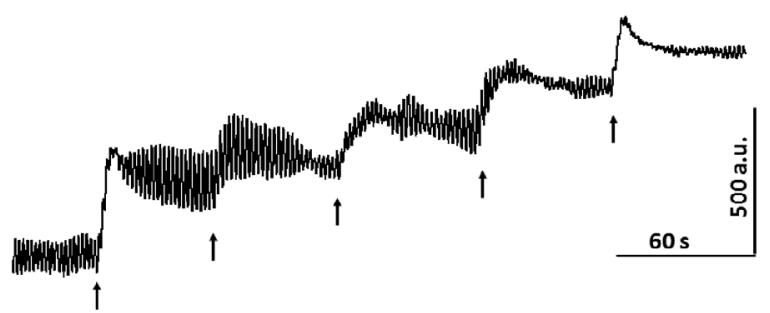

Figure 1. (A) Original recordings of an electrically evoked field EPSP in a control neocortex slice; and (B) of a population spike sitting on the fEPSP in a control hippocampus slice; with analysis parameters displayed; (C) Spontaneous contractions of an isolated and suspended ileum segment; amplitude and tone of the contractions are displayed. Maximal contraction was evoked with $\mathrm{KCl}$ solution (indicated by arrow); (D) Cumulative administration of ACh $(0.25,0.5,1,2,4 \mu \mathrm{M})$ to an ileum segment indicated by arrows.

slices, the population spike amplitude (POPS) and the initial slope of the EPSP were evaluated (Figure 1(B)). The amplitude of an eventual second population spike evoked at a test stimulation intensity of $2 \mathrm{~T}$ was also measured. One-way ANOVA (with Levene's test for homogeneity of variances and Tukey's post-hoc test, p < 0.05) was used for statistical analysis to estimate the differences between control and each treated group. Data are presented as means \pm S.E.M. 76 neocortical and 37 hippocampal slices were tested, originating from 38 rats.

\subsection{Motility Recording on Ileum Segments}

After decapitation, the abdomen of the rats was opened and $1 \mathrm{~cm}$ long segments of the ileum were resected. The isolated ileum segments were suspended before the recording in an organ bath (Experimetria Ltd., Budapest, Hungary) containing oxygenated rat Tyrode solution at $39^{\circ} \mathrm{C}$ for 30 minutes and were washed through with fresh solution every 15 minutes. The composition of the Tyrode solution was (in mM): $\mathrm{NaCl} 136.9 ; \mathrm{KCl}_{2.7} ; \mathrm{NaHCO}_{3}$ 11.9; $\mathrm{KH}_{2} \mathrm{PO}_{4}$ 0.32; $\mathrm{MgSO}_{4}$ 0.98; $\mathrm{CaCl}_{2}$ 1.8; glucose 5.5; $\mathrm{pH}$ 7.4. Under these conditions, suspended ileum segments displayed spontaneous rhythmic contractions. The tonicity and contraction amplitude (Figure 1(C)) of the longitudinal smooth muscle were recorded by a mechanosensor. Eight different concentrations $(0.25 ; 0.5 ; 1$; $2 ; 4 ; 8 ; 16 ; 32 \mu \mathrm{M}$ ) of ACh were cumulatively added (Figure 1(D)). After the ACh series, washout was performed, and then the maximal contraction of each segment was elicited with $0.25 \mathrm{M} \mathrm{KCl}$. Relative amplitude and tonicity data were calculated as a fraction of this maximal contraction (Figure $\mathbf{1}(\mathrm{C})$ ). Contraction patterns were filtered (low-pass at $10 \mathrm{~Hz}$ ) and amplified (Experimetria Ltd., Budapest, Hungary). For data recording and analysis, a home-developed software was used. 38 ileum segments originating from 38 rats were tested. For statistical analysis, the same methods as for brain slice experiments were used; data are plotted as means \pm S.E.M.

\section{Results}

Altogether 32 animals were treated intragastrically with Sumi-Alpha ${ }^{\circledR}$ at a dose of $20 \mathrm{mg} / \mathrm{bwkg}$ which corresponds to $\mathrm{LD}_{50} / 4$. In case of 10 rats, severe choreoathetosis developed within 1 - $2 \mathrm{~h}$ after treatment, these animals 
were euthanized. The other animals also showed signs of discomfort, but no specific symptoms.

\subsection{Basic Excitability of Brain Slices}

In neocortical slices, the stimulation voltage threshold values necessary to evoke fEPSPs were significantly higher in the one-day and two-day treated groups than in the xylene control group (Table 1). The early component of the fEPSP was slightly but not significantly increased by both xylene and esfenvalerate. The amplitude of the late component was significantly lower in the xylene group than in the phys. salt group, whereas it was significantly higher in the two-day treated group than in the xylene group (Figure 2).

In case of the hippocampal slices, the stimulation threshold values did not differ significantly among the groups (Table 1). There was no difference among the EPSP slope values either. However, the population spike amplitude was significantly smaller in the two-day and seven-day treated groups than in the xylene control group. In contrast, the occurrence and amplitude of a second population spike was significantly higher in the seven-day esfenvalerate group than in the xylene group. This could be seen as a tendency in the two-day treated group as well (Figure 3).

\subsection{Plasticity in Brain Slices}

Long-term plasticity was tested by the induction of LTP, in neocortical slices, the early component of the fEPSP was increased by ca. $40 \%$ in the control groups after repetitive stimulation. In the one-day, two-day and seven-day esfenvalerate-treated groups, this enhancement was somewhat smaller: $16 \%, 26 \%$ and $27 \%$, respectively. These differences are, however, not significant compared to the control. In hippocampal slices, the increase of population spikes was $30 \%$ in the phys. salt control group and $45 \%$ in the xylene control group. The corresponding value was $47 \%, 37 \%$ and $30 \%$ in the one-day, two-day and seven-day esfenvalerate-treated groups, respectively. Thus, the seven-day treated group showed a significantly smaller enhancement than the xylene control group (Figure 4).

\section{A}
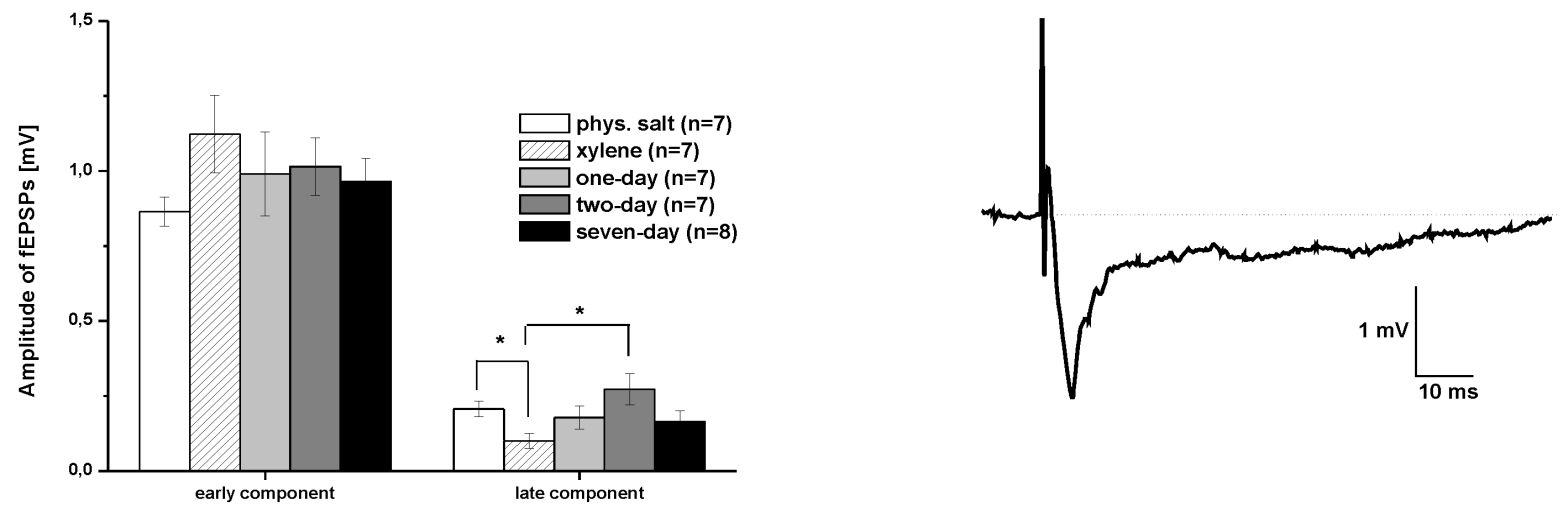

Figure 2. (A) Amplitude of early and late components of the evoked fEPSPs in neocortical slices. * denote significant differences $(p<0.05)$; $(B)$ Sample fEPSP recorded in a neocortical slice originating from a rat two days after esfenvalerate treatment. The late component is more prominent than in control slices.

Table 1. Voltage threshold values necessary to evoke field EPSPs in neocortical and population spikes in hippocampal slices (in Volts, mean \pm S.E.M.). ${ }^{*}$ denotes significant differences compared to the xylene control group $(\mathrm{p}<0.05)$.

\begin{tabular}{ccccc}
\hline Treatment group & Phys. salt control & Xylene control & $\begin{array}{c}\text { One day after } \\
\text { esfenvalerate }\end{array}$ & $\begin{array}{c}\text { Two days after } \\
\text { esfenvalerate }\end{array}$ \\
\hline Neocortex & $1.94 \pm 0.15$ & $1.56 \pm 0.13$ & $2.16 \pm 0.12^{*}$ & $2.16 \pm 0.18^{*}$ \\
esfenvalerate & $1.87 \pm 0.06$ \\
Hippocampus & $2.26 \pm 0.11$ & $2.61 \pm 0.17$ & $2.42 \pm 0.19$ & $2.49 \pm 0.15$ \\
\hline
\end{tabular}


A
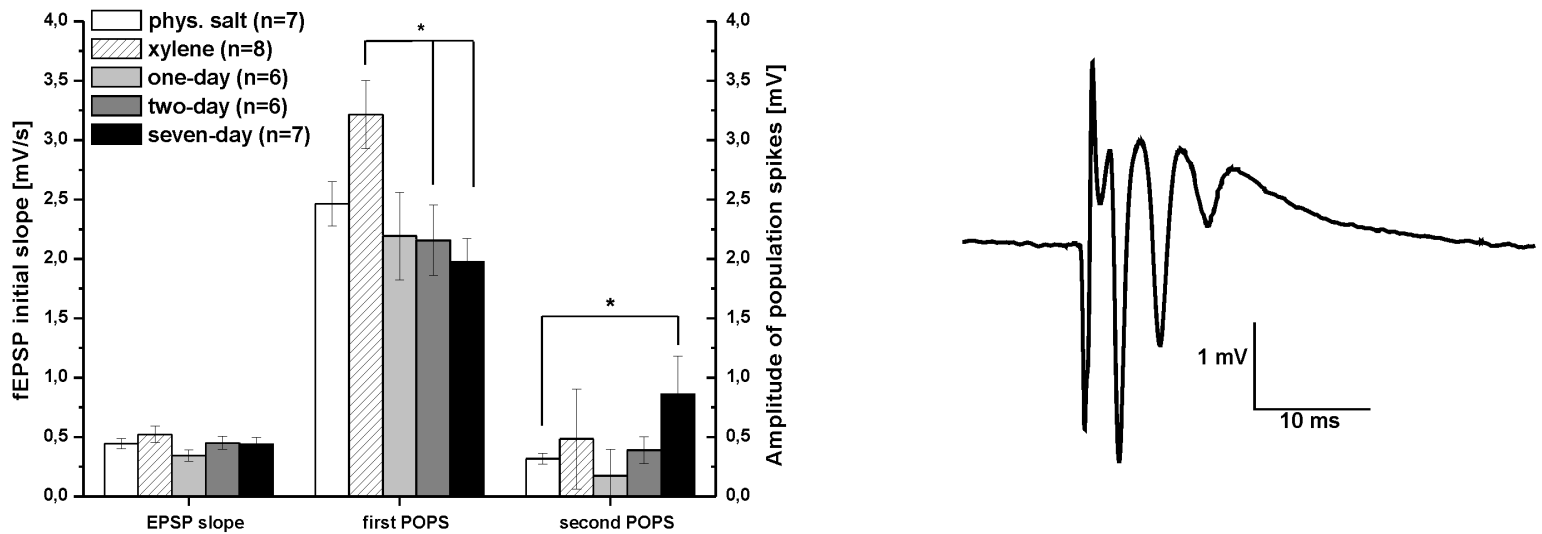

Figure 3. (A) EPSP slope and amplitudes of first and second population spike in hippocampal slices. ${ }^{*}$ denote significant differences $(\mathrm{p}<0.05)$; (B) Sample trace recorded in a hippocampal slice originating from a rat seven days after esfenvalerate treatment. A big second and a small third population spike appeared after the first one.

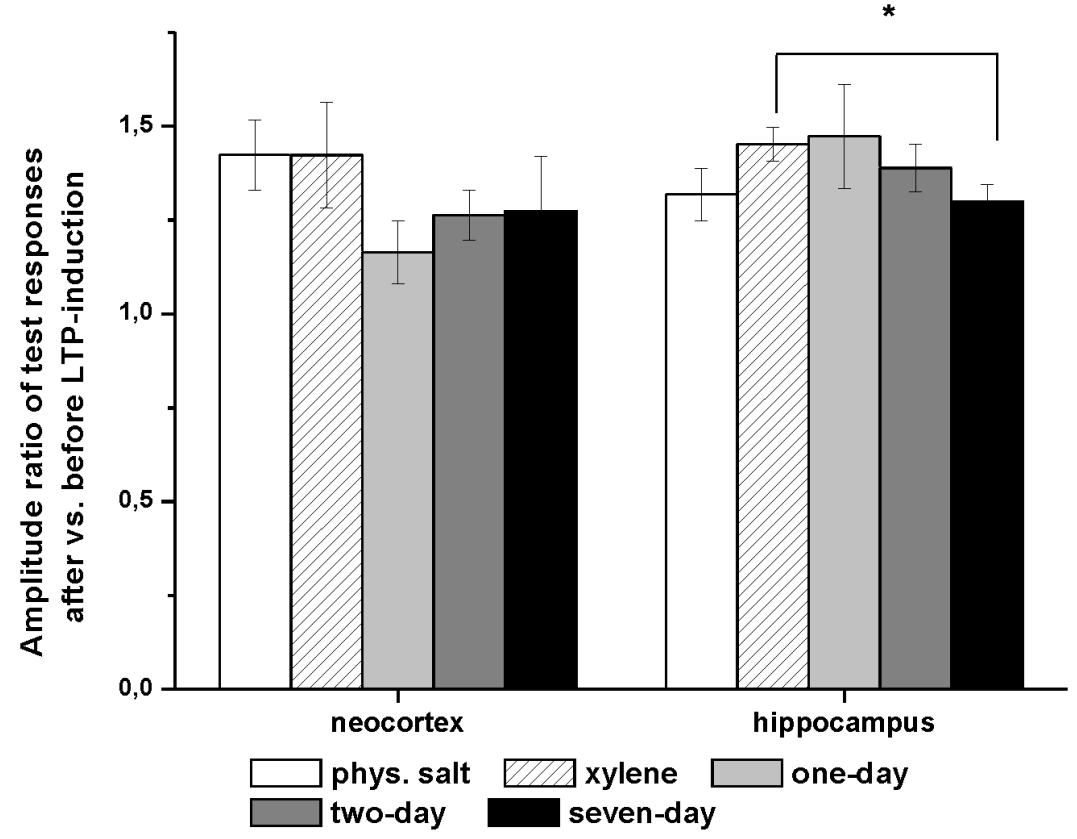

Figure 4. Long-term synaptic enhancement was characterized with induction of LTP. The amplitude ratio of evoked responses after/before repetitive stimulation is plotted for neocortex and hippocampus. ${ }^{*}$ denotes a significant difference $(\mathrm{p}<0.05)$.

\subsection{Seizure Susceptibility of Neocortical Brain Slices}

The slices treated for 60 min with 4-AP displayed spontaneous activity both of ictal (long, complex seizure episodes) and interictal (single discharges) type. Recordings were analyzed according to the following parameters: latency time of first spontaneous episode, latency of first ictal (seizure) episode, number of ictal and interictal episodes during the second 30 min of 4-AP perfusion. The convulsant increased the amplitude of both the early and late components of fEPSPs, though the degree of this increase did not differ significantly among the slices originating from control and esfenvalerate-treated rats. The quantity and parameters of the spontaneous activity were not clearly different, either. Unfortunately, the activity of individual slices in each group was considerably 
different, leading to large error margins. The group examined two days after esfenvalerate treatment seems more susceptible than the others; spontaneous activity was more abundant and developed faster than in the other groups (Table 2).

\subsection{Motility Recording on Ileum Segments}

Cumulative administration of ACh first lead to an increase in amplitude of the contractions, but at higher concentrations (beginning from $1 \mu \mathrm{M}$ ), the contractions rather decreased. This can be explained by the fact that ACh also increases the baseline tension (tonicity) of the ileum segments which impairs their ability to contract and relax with high amplitude. For this reason, the recordings with $1 \mu \mathrm{M}$ ACh and above are considered as not suitable for analysis of contraction amplitude and the data derived from these recording segments are omitted from the figure. Compared to the phys. salt control, xylene significantly increased the amplitude of baseline contractions ( $0 \mu \mathrm{M} \mathrm{ACh}$ ), and both esfenvalerate (two-day group) and xylene increased contractions at low ( 0.25 and $0.5 \mu \mathrm{M})$ ACh concentrations (Figure 5).

ACh dose-dependently increased the tonicity of ileum segments, there were no significant differences among the different treatment groups in this respect. The only significant difference was seen between the control and xylene group at the administration of $8 \mu \mathrm{M}$ ACh; the tonicity of the xylene group was lower (Figure 6).

\section{Discussion}

The present study shows that the insecticide Sumi-Alpha ${ }^{\circledR}$ (active ingredient: esfenvalerate) causes some functional changes in rat nervous system and intestine, when administered orally at a $\mathrm{LD}_{50} / 4$ dose. Some of these changes lasted at least a week.

Historically, pyrethroids were divided into two subclasses based on the intoxication syndromes they cause. Type I pyrethroids (which do not contain a cyano group on the $\alpha$ carbon atom) provoke the T (tremor) syndrome, while Type II pyrethroids (which contain a cyano group on the $\alpha$ carbon atom) cause choreoathetosis and salivation (CS syndrome). Traditionally, esfenvalerate belongs to the Type II group, but according to more recent studies, it has rather mixed Type I/II characteristics [12]. In our study, the animals that developed intoxication symptoms displayed first tremor and salivation, then writhing convulsions, so we observed all known acute signs of pyrethroid poisoning, reflecting nervous system hyperexcitation. However, as our aim was to explore the effects of relatively low-level exposure which does dot elicit quickly developing specific symptoms, these animals were excluded from the experiments.

There are practically no available studies dealing with basic mammalian neuronal functions after in vivo exposure to pyrethroids. The molecular target of pyrethroids is the voltage-gated sodium channel; by modifying its

Table 2. Effect of esfenvalerate treatment on the increase in field EPSPs and pattern of spontaneous activity evoked by perfusion with 4-amino-pyridine. Data are presented as mean \pm S.E.M.

\begin{tabular}{|c|c|c|c|c|c|}
\hline Treatment group & $\begin{array}{l}\text { Phys. salt } \\
\text { control }\end{array}$ & Xylene control & $\begin{array}{l}\text { One day after } \\
\text { esfenvalerate }\end{array}$ & $\begin{array}{l}\text { Two days after } \\
\text { esfenvalerate }\end{array}$ & $\begin{array}{l}\text { Seven days after } \\
\text { esfenvalerate }\end{array}$ \\
\hline $\begin{array}{l}\text { Increase of early } \\
\text { component [\%] }\end{array}$ & $45.9 \pm 10.1$ & $55.9 \pm 15.3$ & $29.9 \pm 19.1$ & $62.2 \pm 12.9$ & $53.8 \pm 9.6$ \\
\hline $\begin{array}{l}\text { Increase of late } \\
\text { component [\%] }\end{array}$ & $147.3 \pm 51.1$ & $494.9 \pm 263.5$ & $200 \pm 86.1$ & $101.6 \pm 38.7$ & $187.3 \pm 106.7$ \\
\hline $\begin{array}{l}\text { No. of slices with } \\
\text { ictal activity }\end{array}$ & $4 / 8$ & $4 / 8$ & $3 / 8$ & $3 / 7$ & $2 / 8$ \\
\hline $\begin{array}{l}\text { Latency of first } \\
\text { spontaneous activity [min] }\end{array}$ & $18.58 \pm 5.53$ & $20.90 \pm 5.27$ & $26.36 \pm 11.39$ & $14.94 \pm 5.39$ & $16.77 \pm 3.62$ \\
\hline $\begin{array}{l}\text { Latency of first ictal } \\
\text { activity [min] }\end{array}$ & $28.80 \pm 6.08$ & $44.96 \pm 7.89$ & $28.97 \pm 14.05$ & $20.13 \pm 10.50$ & $36.75 \pm 4.15$ \\
\hline No. of ictal episodes & $2.88 \pm 1.94$ & $1.88 \pm 1.55$ & $2.43 \pm 2.42$ & $5.86 \pm 5.59$ & $0.88 \pm 1.28$ \\
\hline No. of interictal episodes & $12.88 \pm 11.70$ & $17.25 \pm 16.54$ & $1.25 \pm 1.06$ & $53.60 \pm 20.41$ & $27.14 \pm 12.50$ \\
\hline $\begin{array}{l}\text { Frequency of spontaneous } \\
\text { episodes }[1 / \mathrm{min}]\end{array}$ & $0.65 \pm 0.12$ & $0.96 \pm 0.11$ & $0.43 \pm 0.03$ & $2.30 \pm 0.96$ & $1.17 \pm 0.37$ \\
\hline
\end{tabular}




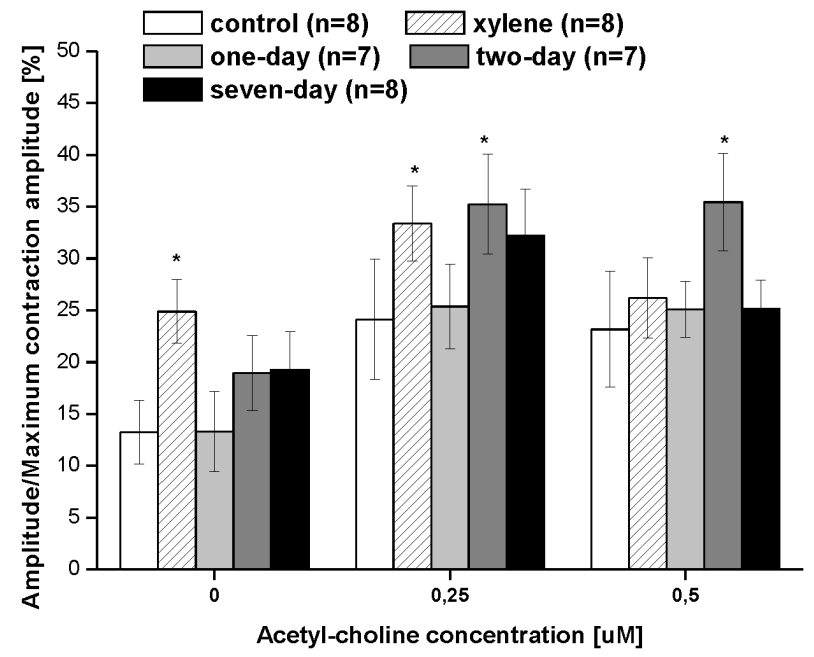

Figure 5. Contraction amplitude of isolated ileum segments during cumulative administration of ACh into the organ bath, compared to maximal contraction elicited with $\mathrm{KCl} .{ }^{*}$ denotes a significant difference compared to the (phys. salt) control group $(\mathrm{p}<0.05)$.

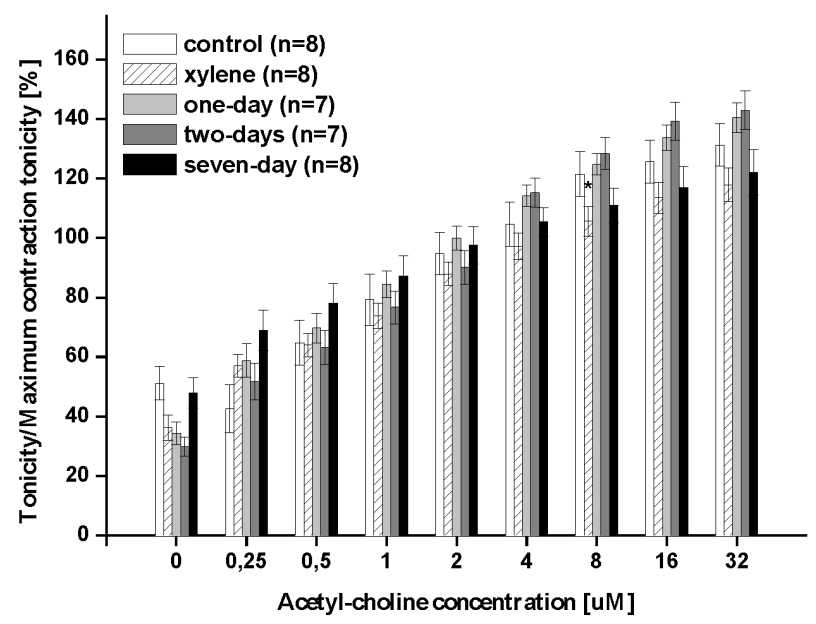

Figure 6. Tonicity of isolated ileum segments during cumulative administration of ACh into the organ bath, compared to the tonicity of maximal contraction elicited with $\mathrm{KCl}$. ${ }^{*}$ denotes a significant difference compared to the (phys. salt) control group $(\mathrm{p}<0.05)$.

kinetics, these compounds may cause the overexcitation or inhibition of neurons and muscle fibers. In case of in vitro administration, usually the inhibitory changes are predominant. In in vitro systems, it is more probable that the concentration of the pyrethroid reaches such a high level which already leads to the depolarization block of the neurons, inhibiting the creation and conduction of action potentials [13].

On the other hand, behavioral studies examining the effects of pyrethroids are quite abundant. However, these results are not directly comparable with our experiments carried out on isolated neuronal circuits present in brain slices. Pyrethroids decrease activity level, impair motor functions and sensomotor integration [14]. It has also been shown that they impair certain learning and memory functions, e.g. spatial learning studied by the Morris water maze [15] or fear conditioning studied by stepdown test [16].

When analyzing the functions of the brain slices originating from esfenvalerate-treated animals, changes of both inhibitory and excitatory type could be observed. One and two days after treatment, the voltage thresholds 
necessary to evoke fEPSPs in neocortex slices was elevated, this suggests a decrease in the basic excitability of the cortex. In hippocampal slices, the population spike amplitudes were lower two and seven days after treatment than in control slices. As for the hyperexcitatory signs, in neocortex slices, the late component of the fEPSPs was increased two days after treatment, while in hippocampal slices, the amplitude of the second population spike was significantly increased seven days after treatment. The appearance of epileptiform potentials is not surprising, as high-dose type II pyrethroids evoke epileptic activity in mammals [17].

Seizure susceptibility of the slices (examined by administration of 4-AP) was slightly but not significantly altered by esfenvalerate treatment of the animals. Convulsant susceptibility of the slices originating from treated animals tended to be somewhat higher, but the data showed very high variability. Exposure to pyrethroids leads to acute seizures which disappear after treatment within a few hours. Our recordings took place 1 - 7 days after treatment, when susceptibility might be little higher, bur spontaneous seizure activity is not expected any more.

As for plasticity phenomena, a decreased LTP could be seen in both brain areas after esfenvalerate treatment. This alteration was significant in hippocampal slices seven days after treatment. LTP is considered as the synaptic basis for the storage of memory traces and pyrethroids have been shown to impair learning as mentioned above.

The functioning of the brain slices originating from rats treated with xylene did not differ considerably from those treated with phys. salt solution. The only difference was that in neocortical slices, the late component was significantly smaller in the xylene control group than in the phys. salt control group. This may be due to chance, as solvents rarely have acute effects; they rather tend to change the active ingredient's toxicity by changing its pharmacokinetic parameters. In a study comparing the toxicity of pure fenvalerate with a commercial compound containing organic solvent, higher toxicity of the latter was observed [18]. The adverse effects of xylene on nervous system rather occur at chronic exposure [19].

Esfenvalerate is rapidly eliminated from the organism after oral exposure. In case of a lower dose $(2.5 \mathrm{mg} / \mathrm{kg})$ than that used by us, almost the whole amount of the chemical was cleared from the body of rats within 2 days; but traces were still detectable in adipose tissue 7 days after treatment [7]. In our study, we detected some alterations in the hippocampus even 7 days after treatment (epileptiform populations spikes, diminished LTP); at this time point, probably there was no substantial amount of esfenvalerate present in the brain any more. The observed changes may be the aftereffects of the acute alterations.

Pyrethroid formulations may cause gastrointestinal symptoms, including diarrhea after accidental oral exposure in humans [20] or experimental exposure in animals [21]. No data are available for ileum motility functions after in vivo exposure to pyrethroids. In vitro tests on isolated ileum segments revealed that in vitro application of pyrethroids may have a biphasic or antagonistic effect on electrically evoked or cholinergic contractions [22] [23].

As for our ileum motility results, both spontaneous and ACh-elicited contractions were different in treated vs. control rats. The solvent, xylene and esfenvalerate increased the amplitude of contractions in the low ACh concentration range 2 days after treatment. In summary, it seems that the basic excitability and ACh sensitivity of the ileal longitudinal muscle and/or enteral neurons was shifted by Sumi-Alpha ${ }^{\circledR}$ treatment; but a considerable part of the effects is attributable to the solvent.

\section{Conclusion}

In conclusion, a relatively high, single oral dose of the esfenvalerate-containing pyrethroid insecticide SumiAlpha $^{\circledR}$ exerted mild and temporary effects on the elementary brain functions and intestine functions of the rat. Although recently developed pyrethroids show a very good selective toxicity for insects over mammals, their application needs caution. In vitro test systems may be useful to reveal mild functional changes caused by different chemicals at a low level of exposure, which does not yet lead to specific poisoning symptoms or morphological alterations.

\section{References}

[1] Casida, J.E. (1980) Pyrethrum Flowers and Pyrethroid Insecticides. Environmental Health Perspectives, 34, $189-202$. http://dx.doi.org/10.1289/ehp.8034189

[2] Narahashi, T. (1992) Nerve Membrane Na+ Channels as Targets of Insecticides. Trends in Pharmacological Sciences, 13, 236-241. http://dx.doi.org/10.1016/0165-6147(92)90075-H 
[3] Catterall, W.A. (2000) From Ionic Currents to Molecular Mechanisms: The Structure and Function of Voltage-Gated Sodium Channels. Neuron, 26, 13-25. http://dx.doi.org/10.1016/S0896-6273(00)81133-2

[4] Marban, E., Yamagishi, T. and Tomaselli, G.F. (1998) Structure and Function of Voltage-Gated Sodium Channels. The Journal of Physiology, 508, 647-657. http://dx.doi.org/10.1111/j.1469-7793.1998.647bp.x

[5] Vais, H., Williamson, M.S., Devonshire, A.L. and Usherwood, P.N. (2001) The Molecular Interactions of Pyrethroid Insecticides with Insect and Mammalian Sodium Channels. Pest Management Science, 57, 877-888. http://dx.doi.org/10.1002/ps.392

[6] Song, J.H. and Narahashi, T. (1996) Modulation of Sodium Channels of Rat Cerebellar Purkinje Neurons by the Pyrethroid Tetramethrin. Journal of Pharmacology and Experimental Therapeutics, 277, 445-453.

[7] Isobe, N., Kaneko, H., Shiba, K., Saito, K., Ito, S., Kakuta, N., Saito, A., Yoshitake, A. and Miyamoto, J. (1990) Metabolism of Esfenvalerate in Rats and Mice and Effects of Its Isomers on Metabolic Fates of Esfenvalerate. Journal of Pesticide Science, 15, 159-168. http://dx.doi.org/10.1584/jpestics.15.159

[8] Parker, C.M., Albert, J.R., Vangelder, G.A., Patterson, D.R. and Taylor, J.L. (1985) Neuropharmacologic and Neuropathologic Effect of Fenvalerate in Mice and Rats. Fundamental and Applied Toxicology, 5, 278-286. http://dx.doi.org/10.1016/0272-0590(85)90075-2

[9] Furness, J.B. (2000) Types of Neurons in the Enteric Nervous System. Journal of the Autonomic Nervous System, 81, 87-96. http://dx.doi.org/10.1016/S0165-1838(00)00127-2

[10] Galligan, J.J. (2002) Pharmacology of Synaptic Transmission in the Enteric Nervous System. Current Opinion in Pharmacology, 2, 623-629. http://dx.doi.org/10.1016/S1471-4892(02)00212-6

[11] Varró, P., Szigyártó, I.Cs., Gergely, A., Kálmán, E. and Világi, I. (2013) Carbon Nanotubes Exert Basic Excitatory Enhancement in Rat Brain Slices. Acta Biologica Hungarica, 64, 137-151. http://dx.doi.org/10.1016/S1471-4892(02)00212-6

[12] Breckenridge, C.B., Holden, L., Sturgess, N., Weiner, M., Sheets, L., Sargent, D., Soderlund, D.M., Choi, J.S., Symington, S., Clark, J.M., Burr, S. and Ray, D. (2009) Evidence for a Separate Mechanism of Toxicity for the Type I and the Type II Pyrethroid Insecticides. Neurotoxicology, 30, S17-S31. http://dx.doi.org/10.1016/j.neuro.2009.09.002

[13] Tabarean, I.V. and Narahashi, T. (1998) Potent Modulation of Tetrodotoxin-Sensitive and Tetrodotoxin-Resistant Sodium Channels by the Type II Pyrethroid Deltamethrin. Journal of Pharmacology and Experimental Therapeutics, 284, 958-965.

[14] Wolansky, M.J. and Harrill, J.A. (2008) Neurobehavioral Toxicology of Pyrethroid Insecticides in Adult Animals: A Critical Review. Neurotoxicology and Teratology, 30, 55-78. http://dx.doi.org/10.1016/j.ntt.2007.10.005

[15] Zhang, Y., Wang, Q., Wang, Z., Zhang, Q. and Zhang, Y. (2008) Neurobehavior and Learning and Memory of Mice after Postnatal Exposure to Fenvalerate. Journal of Toxicology, 2, 005.

[16] Gao, B., Liu, Z. and Liu, X. (2009) Effect of Fenvalerate on the Activity of Acetylcholinesterase and Learning and Memory Function in Mouse Brain Tissue. Occupation and Health, 19, 005.

[17] Vijverberg, H.P. and van den Bercken, J. (1990) Neurotoxicological Effects and the Mode of Action of Pyrethroid Insecticides. Critical Reviews in Toxicology, 21, 105-126. http://dx.doi.org/10.3109/10408449009089875

[18] Williamson, E.G., Long, S.F., Kallman, M.J. and Wilson, M.C. (1989) A Comparative Analysis of the Acute Toxicity of Technical-Grade Pyrethroid Insecticides and Their Commercial Formulations. Ecotoxicology and Environmental safety, 18, 27-34. http://dx.doi.org/10.1016/0147-6513(89)90089-4

[19] Wang, X.L., Jin, X.P., Fu, H., Chen, Z.Q., Da, C.D., Huang, X.F. and Ding, B.Q. (1999) Xylene-Induced Effects on Brain Neurotransmitters, Behavior and Fos Protein in Rats. Biomedical and Environmental Sciences, 12, 116-124.

[20] Yang, P.Y., Lin, J.L., Hall, A.H., Tsao, T.C. and Chern, M.S. (2002) Acute Ingestion Poisoning with Insecticide Formulations Containing the Pyrethroid Permethrin, Xylene, and Surfactant: A Review of 48 Cases. Journal of Toxicology. Clinical Toxicology, 40, 107-113. http://dx.doi.org/10.1081/CLT-120004397

[21] Neuschl, J., Kacmar, P. and Poracova, J. (1995) Toxicologic Evaluation of Supermethrin, a Pyrethroid Insecticide, in Rabbits and Pheasants. Veterinarni Medicina, 40, 383-386.

[22] Tonini, M., Costa, L.G., Candura, S.M., Olibet, G., Rizzi, C.A., Garlaschelli, L. and Manzo, L. (1989) Interaction of the Pyrethroid Insecticides Tetramethrin and Cypermethrin with Enteric Cholinergic Transmission in the Guinea-Pig. Neurotoxicology, 10, 707-715.

[23] Stankovic, J., Varagic, V. and Milovanovic, S. (2005) Modulatory Effects of Neurotoxic Insecticides on the Peripheral and Central GABA-Ergic Actions. Acta Veterinaria, 55, 193-201. http://dx.doi.org/10.2298/AVB0503193S 


\section{Abbreviations}

ACh-acetyl-choline;

4-AP-4-aminopyridine;

ACSF_-artificial cerebrospinal fluid;

fEPSP_field excitatory postsynaptic potential;

POPS—population spike;

LTP-long-term potentiation. 